\title{
Granulomorphometry: A suitable tool for identifying hydrophobic and disulfide bonds in $\beta$-lactoglobulin aggregates. Application to the study of $\beta$-lactoglobulin aggregation mechanism between 70 and $95^{\circ} \mathrm{C}$
}

\author{
J. Petit, ${ }^{1}$ A.-L. Herbig, A. Moreau, J.-F. Le Page, T. Six, and G. Delaplace \\ INRA UR638-Processus aux Interfaces et Hygiène des Matériaux, BP 20039, 59651 Villeneuve d'Ascq Cedex, France
}

\begin{abstract}
This work deals with the investigation of $\beta$-lactoglobulin ( $\beta$-LG) aggregation by granulomorphometry. In the first part of this study, we showed that the binding interactions involved in aggregate structure could be identified by their appearance in granulomorphometric pictures. The reliability of this analytical approach was demonstrated by comparing the appearance of $\beta$-LG aggregates in the presence and absence of a thiol-blocking agent ( $N$-ethylmaleimide). The translucency of the aggregates was associated with hydrophobic interactions and their opacity was associated with disulfide bonds. We state, based on the morphology of the aggregates, along with the color of protein aggregates and insoluble materials, that hydrophobic interactions had a better water-holding capacity than disulfide bonds. Additionally, our results suggest that disulfide and hydrophobic bonds compete for $\beta$-LG aggregate shaping. In the second part of this work, interesting features of granulomorphometry useful for identifying aggregate binding interactions were highlighted to clarify the effect of temperature on the aggregation mechanisms occurring in a $\beta-\mathrm{LG}$ concentrate with a moderate calcium content $\left(6.6 \mathrm{mmol} \cdot \mathrm{L}^{-1}\right)$. Heat treatment experiments were performed between 70 and $95^{\circ} \mathrm{C}$, and granulomorphometric measurements (aggregate size, aggregate number, and gray level of the picture) were conducted at different sampling times up to $4 \mathrm{~h}$. Results, which were interpreted in light of calculated $\beta-\mathrm{LG}$ denaturation levels, revealed that the aggregation mechanism could be split into 2 steps. Initially, $\beta-\mathrm{LG}$ denatured quickly, leading to fast $\beta-\mathrm{LG}$ aggregation by disulfide bonds. The denaturation rate then declined, which drastically slowed the disulfide aggregation mechanism. From that point on, a second aggregation path became preponderant. It consisted of the agglomeration of small aggregates by hydrophobic
\end{abstract}

Received January 3, 2011.

Accepted April 7, 2012.

${ }^{1}$ Corresponding author: jeremy.petit@centraliens.net interactions and resulted in the formation of large aggregates containing both interaction types. This second aggregation mechanism was clearly favored at high temperatures because it was not detected in our experiments at temperatures below $85^{\circ} \mathrm{C}$.

Key words: granulomorphometry, $\beta$-lactoglobulin, disulfide bond, hydrophobic interaction

\section{INTRODUCTION}

Globular proteins (especially $\beta-\mathrm{LG}$ ) are commonly used as functional ingredients in many kinds of dairy food products. The industrial thermomechanical treatments influence $\beta-\mathrm{LG}$ denaturation, along with the aggregation and fouling mechanisms of $\beta$-LG. Thus, heat treatments, which are carried out to ensure sanitary requirements, are responsible for the size and nature of aggregates as well as the associated functionalities of dairy products, such as their gelation, emulsification, water retention, and stabilizing effect. The means by which the aggregation process occurs also influences the fouling behavior of heated dairy solutions, in particular because $\beta$-LG aggregates and deposits have the same precursory species (molten globule $\beta$-LG; BlanpainAvet et al., 2012). Fouling is defined as protein deposition on the hot surfaces of heat exchangers, and it results in a decrease in heat exchange (René and Lalande, 1988; Benning et al., 2003), a greater pressure drop (Grijspeerdt et al., 2004; Fryer et al., 2006), and bacterial growth (Fryer et al., 2006; Jun and Puri, 2007). Deposit formation in industrial heat exchangers makes frequent cleanings necessary, resulting in the excessive use of water and harsh chemicals (René and Lalande, 1988; Georgiadis et al., 1998). To limit the phenomenon of fouling, the lead-up and concomitant mechanisms, respectively, $\beta-\mathrm{LG}$ denaturation and aggregation, need to be clearly understood. Thus, the main information on $\beta$-LG denaturation and aggregation reported in the literature were gathered.

Bovine $\beta-\mathrm{LG}$, one of the main whey proteins (along with $\alpha$-LA and BSA), accounts for approximately $50 \%$ 
of the whey proteins (Mulvihill and Donovan, 1987; Havea et al., 2001), which corresponds to approximately $3.5 \mathrm{~g} \cdot \mathrm{L}^{-1}$ in milk (Lalande et al., 1989). Its isoelectric point is approximately 5.3 (René and Lalande, 1988) and its denaturation temperature is estimated at approximately $77^{\circ} \mathrm{C}$ (Nielsen et al., 1995; Relkin, 1996; Havea et al., 2001; Linmark-Mansson et al., 2005), depending greatly on the chemical environment. The tertiary structure of $\beta-\mathrm{LG}$ is consolidated by 2 disulfide bonds. A free thiol group - $\mathrm{SH}$ is hidden inside its hydrophobic core in the native state (Relkin, 1996; Labouré et al., 2004; Perez and Pilosof, 2004). Under heat or chemical denaturation, $\beta$-LG loses its native tertiary structure to form reactive species, often called "molten globules," which are able to form disulfide bonds with another whey protein via thiol group oxidation or disulfide interchange, which induces an alteration of the $\beta$-LG secondary structure (Mulvihill and Donovan, 1987; Labouré et al., 2004). This constitutes the aggregation phenomenon (Delplace et al., 1997; Santos et al., 2006).

The literature shows that 2 kinds of interactions take part in $\beta$-LG aggregate formation: covalent (disulfide) and noncovalent (hydrogen bonds, van der Waals interaction, etc.) interactions. The competition between these 2 interaction types leads to the formation of 2 main types of aggregates, depending on the environmental conditions. On one hand, at a low temperature $\left(<85^{\circ} \mathrm{C}\right.$; Hongsprabhas and Barbut, 1997; Spiegel, 1999 ), a $\mathrm{pH}$ close to the $\beta-\mathrm{LG}$ isoelectric point (Stading and Hermansson, 1991; Gault and Fauquant, 1992; Ikeda and Li-Chan, 2004), high ionic strength (Barbut, 1995a; Ikeda, 2003; Ikeda and Li-Chan, 2004; Nicolai et al., 2011), or high calcium concentration (Lupano et al., 1992; Barbut, 1995b; Hongsprabhas and Barbut, 1997; Nicolai et al., 2011), $\beta$-LG aggregates are mainly formed by hydrophobic interactions: they are rather spherical and rigid (Havea et al., 2004). Their size is important, and they show a good aptitude for water release (Ikeda, 2003), generally associated with a low water-holding capacity (Lupano et al., 1992; Barbut, 1995a; Nicolai et al., 2011). Moreover, hydrophobic aggregates appear opaque on transmission electron micrographs (Barbut, 1995a), which has been explained by the random location of noncovalent interactions.

On the other hand, disulfide interactions predominate at high temperatures $\left(\geq 85\right.$ to $95^{\circ} \mathrm{C}$; Hongsprabhas and Barbut, 1997; Spiegel, 1999; Nicolai et al., 2011), neutral or acidic pH (Stading and Hermansson, 1991; Ikeda, 2003; Ikeda and Li-Chan, 2004; Nicolai et al., 2011), low ionic strength (Barbut, 1995a; Ikeda, 2003), or low calcium content (Gault and Fauquant, 1992; Lupano et al., 1992; Barbut, 1995b; Hongsprabhas and Barbut, 1997). The aggregates formed are smaller, soft, and easily deformable (Havea et al., 2004); they have a translucent aspect in microscopic analysis (transmission electron microscopy, scanning electron microscopy), which is subsequent to their finely stranded structure and small size (Stading and Hermansson, 1991; Barbut, 1995a; Ikeda, 2003; Havea et al., 2004). Several authors (Lupano et al., 1992; Barbut, 1995a; Spiegel, 1999) have ascribed a good water-holding capacity to disulfide aggregates, based on the observation that water molecules bound to these aggregates are difficult to remove by centrifugation or gel squeezing. It is important to note that no unequivocal definition exists for the concept of water-holding capacity in the scientific community. In fact, water-holding capacity sometimes refers to the overall water retained by aggregates, equal to the sum of bound and removable water fractions. With this definition, hydrophobic gels are said to have a better water-holding capacity than disulfide ones (Clare et al., 2007), indicating that hydrophobic interactions are more prone to associate with water than are disulfide bonds.

This brief literature survey characterizing $\beta$-LG aggregates emphasizes the obvious need to develop an analytical technique that is able to relate the appearance of aggregates in solution to the hydration level of their binding interactions (i.e., the total amount of retained water in these aggregates).

As regards the temperature influence on aggregate shaping by hydrophobic and disulfide bonds, Briggs and Hull proposed for the first time in 1945 an aggregation mechanism involving both interaction types (Briggs and Hull, 1945), which was later confirmed by Sawyer (1968) and has been generally agreed on in the dairy community from that time on (Hoffmann and Van Mill, 1997; De La Fuente et al., 2002; Sava et al., 2005). According to Sawyer (1968), the formation of disulfide and noncovalent linked aggregates at near-neutral $\mathrm{pH}$ can be divided in 2 steps. During a primary reaction, small $\beta$-LG aggregates (presumably non-native $\beta$-LG dimers or tetramers) are formed by disulfide bonds. This reaction, occurring at temperatures above $65^{\circ} \mathrm{C}$, is favored at high temperatures, especially around $97.5^{\circ} \mathrm{C}$. Once this primary reaction is initiated, a secondary reaction takes place, which consists of the formation of large aggregates by noncovalent bonds.

In a recent review dealing with advances in $\beta$-LG thermal behavior, De Wit (2009) confirmed this global aggregation mechanism and provided more detail about the temperature ranges associated with disulfide and hydrophobic interactions in $\beta-\mathrm{LG}$ solutions at $\mathrm{pH}$ $>6.8$ and low ionic strength. It is well known that $\beta$-LG keeps its native structure up to $60^{\circ} \mathrm{C}$. Above this temperature, $\beta$-LG unfolds and changes into a molten globule state prone to aggregation. Small aggregates 
(essentially non-native $\beta$-LG dimers) begin to be produced from $65^{\circ} \mathrm{C}$ on, enabling further aggregation (Hoffmann and Van Mill, 1997). De Wit (2009) suggested that hydrophobic and disulfide interactions are concomitant up to $85^{\circ} \mathrm{C}$ and lead to the formation of large-sized aggregates. Above $85^{\circ} \mathrm{C}$, the mechanism of $\beta-\mathrm{LG}$ aggregation is dominated by disulfide bond formation, and these short-range interactions are expected to contract the particle radius and strengthen the aggregate structure. Therefore, the aggregate size declines from 85 to $105^{\circ} \mathrm{C}$, where the noncovalent interactions become absolutely negligible. These mechanisms may be altered in high-ionic-strength environments or in the presence of a significant calcium concentration, such as in the conditions of our study.

In sum, this literature review revealed that the nature of binding interactions governs $\beta$-LG aggregate morphological features (size, shape, and color) and these interactions are thus expected to have a strong effect on the functionalities of heat-treated $\beta$-LG solutions, such as their mouthfeel, color, aptitude for gelation, and water-holding capacity. According to the state of the art, however, it seems difficult to relate the appearance of aggregates to the nature of their binding interactions. Moreover, although many authors have been interested in shedding light on the dependence of aggregation mechanisms on process parameters, such as temperature, it is still impossible to propose guidelines for selecting the aggregate binding interactions and their water-holding capacities from an adequate choice of process parameters. For all these reasons, our study aimed to show interesting features of granulomorphometry as they relate to identifying binding interactions and elucidating aggregation mechanisms.

First, the suitability of granulomorphometry for identifying aggregate binding interactions was demonstrated by performing heat-denaturation experiments on a $\beta-\mathrm{LG}$ concentrate in the presence and absence of a thiol-blocking agent. Comparing the granulomorphometric pictures of $\beta$-LG aggregates and unsolvated dispersed phases (insoluble materials and air bubbles) permitted us to connect the water-holding capacity of aggregates to their appearance in pictures. The means by which binding interactions influence the aggregate water-holding capacity is also discussed from these experiments.

The second part of this study consisted of applying this granulomorphometric approach to clarify the role played by temperature in $\beta$-LG aggregation mechanisms. Heat treatment experiments were carried out between 70 and $95^{\circ} \mathrm{C}$, and the temporal evolution of aggregate morphological characteristics (shape, color, and size) was recorded by granulomorphometry. The acquired results, interpreted in relation to the $\beta$-LG denaturation level, permitted a better understanding of how binding interactions compete and confer their functionalities on $\beta$-LG aggregates in concentrated solutions.

\section{MATERIALS AND METHODS}

\section{Chemicals and Reagents}

For each experiment, a $53 \mathrm{~g} \cdot \mathrm{L}^{-1}$ [i.e., $2.9 \mathrm{mmol} \cdot \mathrm{L}^{-1}$, by considering a $18.3-\mathrm{kDa}$ molar mass (Verheul et al., $1998)$ in the calculation] $\beta$-LG solution was prepared by scattering $6 \mathrm{~g}$ of an industrial $\beta$-LG powder (composition: $\beta$-LG $88.85 \%$, $\alpha$-LA $<0.01 \%$, calcium $0.03 \%$, phosphate $0.07 \%$, sodium $0.76 \%$, lactose $0.4 \%$ ) in 94 $\mathrm{g}$ of deionized water (Millipore, Bedford, MA). Therefore, $660 \mu \mathrm{L}$ of a molar calcium chloride (96\%, Prolabo; VWR International, West Chester, PA) solution was added to obtain a stock solution containing $5.3 \% \beta-\mathrm{LG}$ and $6.6 \mathrm{mmol} \cdot \mathrm{L}^{-1}$ of calcium chloride. The composition of this stock solution was chosen so as to simulate an industrial $\beta-\mathrm{LG}$ concentrate. This solution was maintained at $40^{\circ} \mathrm{C}$ for $2 \mathrm{~h}$ for complete dissolution of the $\beta$-LG powder. The $\mathrm{pH}$ of this solution was 6.8 .

To inactivate the $\beta$-LG thiol group, half of the samples were treated with $N$-ethylmaleimide (NEM, Sigma-Aldrich, St. Louis, MO) according to the following protocol adapted from literature (Hoffmann and Van Mill, 1997): $2.9 \mathrm{mmol} \cdot \mathrm{L}^{-1}$ of NEM was added to the $\beta$-LG stock solution, which was allowed to react for $1 \mathrm{~h}$ at ambient temperature. The NEM concentration was chosen to form an equimolar mixture of NEM and $\beta$-LG, which was sufficient to significantly inhibit $\beta$-LG thiol reactivity (Mounsey and O'Kennedy, 2007).

For granulomorphometric analyses, the heat-treated $\beta$-LG samples were diluted 100-fold in deionized water. This allowed accurate granulomorphometric results to be acquired while limiting larger particles to hide the others.

The opacity of unsolvated objects on the granulomorphometric pictures, such as air bubbles and insoluble minerals, was obtained by analyzing a simulated skim milk [composition: $5 \%$ (wt/wt) ultrafiltrate powder (Lactepi 452; Epi Ingredients, Ancenis, France) $+0.7 \%$ (wt/wt) whey protein powder (Promilk 852 FB1; Idi SAS, Arras, France) $+2.9 \%$ (wt/wt) phosphocaseinate powder (Promilk $852 \mathrm{~B}$; Idi SAS)], a $10 \mathrm{~g} \cdot \mathrm{L}^{-1}$ calcium carbonate suspension (Normapur, Prolabo; VWR International), and a $2 \mathrm{~g} \cdot \mathrm{L}^{-1}$ phosphocaseinate (Promilk $852 \mathrm{~B}$; Idi SAS) suspension in deionized water and in ethanol (99\%, Thermo Fisher Scientific, Waltham, MA). 


\section{Heat Treatment}

All thermal denaturation experiments were conducted on 1.4-mL samples in polypropylene vials (Eppendorf, Hamburg, Germany). Samples treated with NEM and those free of NEM were jointly heat treated so as to allow comparison of the experimental data. We chose to preheat the samples to $60^{\circ} \mathrm{C}$ [below the beginning of $\beta$-LG aggregation: $77^{\circ} \mathrm{C}$ (Nielsen et al., 1995; Relkin, 1996; Havea et al., 2001; Linmark-Mansson et al., 2005)] to limit $\beta$-LG denaturation before sample acquisition. This was achieved by first placing samples in a water bath at $62^{\circ} \mathrm{C}$ for $30 \mathrm{~min}$. During the entire heat treatment procedure, the temperature was monitored by using a temperature probe inserted in a reference vial filled with the stock solution.

The rapid temperature increase from $60^{\circ} \mathrm{C}$ to the desired holding temperature was performed by placing the samples in a second water bath, whose temperature was fixed (as a rule) at $10^{\circ} \mathrm{C}$ higher than the holding temperature to shorten the temperature increase time and restrict $\beta$-LG denaturation before sample acquisition.

Once the holding temperature was reached, the samples were placed in a third water bath, whose temperature was fixed at $2^{\circ} \mathrm{C}$ higher than the holding temperature (e.g., $97^{\circ} \mathrm{C}$ for a holding temperature of $95^{\circ} \mathrm{C}$ ). Six holding temperatures were investigated: 70 , $75,80,85,90$, and $95^{\circ} \mathrm{C}$. Sample immersion in this last water bath corresponded to time zero (i.e., the holding time began with sample immersion in the third water bath). At different holding times (10 min, $30 \mathrm{~min}, 1 \mathrm{~h}$, $2 \mathrm{~h}, 3 \mathrm{~h}$, and $4 \mathrm{~h}$ ), the samples were removed and cooled immediately in a beaker half filled with melting ice to stop $\beta$-LG denaturation and aggregation immediately.

It was noted that during these heat treatments, NEM-treated samples had a strong tendency to form gels. Indeed, at 90 and $95^{\circ} \mathrm{C}$, gelation occurred in less than $10 \mathrm{~min}$, whereas at $85^{\circ} \mathrm{C}$, the $\beta$-LG concentrate gelated from the 30-min heat treatment. This explains why no granulomorphometric analysis was performed for these samples. No such propensity for gelation was detected for samples free of NEM.

\section{Granulomorphometry}

In the heat-treated samples, the aggregate sizes were analyzed using a Flow-Cell 200 S-M instrument (Occhio, Angleur, Belgium) granulomorphometer. Granulomorphometry is a recently developed microscopy technique designed to acquire high-quality pictures of particles within a liquid solution. The granulomorphometric analysis consisted of pumping a liquid sample through a $300-\mu \mathrm{m}$-wide flow cell, backlit at a $440-\mathrm{nm}$ wavelength (blue), and obtaining digital pictures from a high-resolution camera with a $0.38-\mu \mathrm{m}$ spatial resolution $(9 \times$ zoom factor $)$. Sample pictures were acquired when the flow was completely stopped so as to ensure good sharpness of the digital pictures obtained.

The granulomorphometer was coupled with image analysis software (Callisto) designed for particle detection by using the gray level difference between the particle and background. It allowed the aggregate number to be counted, the size distribution to be measured, and the analyzed particles to be visualized. In addition, aggregate morphological characteristics, such as area, perimeter, or circularity, could be deduced. In our study, the mean aggregate diameter in volume, abbreviated $\mathrm{D}_{50}$, was calculated by the image analysis software as the average area diameter of all analyzed particles, weighted by their estimated volume. The area diameter was defined as the equivalent diameter of a sphere having the same area in the granulomorphometric pictures as the analyzed particle. This size estimator was very similar to the Sauter mean diameter.

For each run, the mean aggregate size was determined by processing 16 pictures, which corresponded to a few thousand particles, depending on the heat treatment time and temperature. Each sample was analyzed 5 times so as to improve the accuracy of the granulomorphometric parameters determined. Light calibration was performed on deionized water between each sample, with an associated gray level of 200 . The most accurate measurements were obtained with a threshold of 180 for particle detection. The same analytical method was used for acquiring pictures of bubbles, calcium carbonate, and phosphocaseinate particles.

Granulomorphometry has another advantage for studying the microstructure of aggregates. Indeed, the contrast level of the analyzed particles may reveal the ability of the solvent to interact with the dispersed phase. As the background calibration was carried out on the solvent, the solvent color was very light gray (gray level of 200) in the granulomorphometric pictures, whereas opaque particles corresponded to black patches (with a gray level far below 180). We show in the Results section that a contrast decrease inside a particle was indicative of greater solvent (here, water) retention.

\section{Denaturation Level Calculation}

The evolution of the $\beta$-LG denaturation level with time and temperature was calculated by means of the finite difference method implemented with Scilab software (Digiteo, Saclay, France), as presented in a previous work (Petit et al., 2011). These calculations were based on the denaturation mechanism, in which both 
the unfolding and aggregation reactions are described by a kinetic differential equation (Petit et al., 2011), and on the temporal discretization of the experimentally acquired heat profile. We chose to fix the time step to $1 \mathrm{~s}$, which provided sufficient precision for our calculations.

The kinetic parameters of $\beta-\mathrm{LG}$ denaturation related to the $\beta$-LG concentrate used in the current work (composed of $53 \mathrm{~g} \cdot \mathrm{L}^{-1}$ of $\beta-\mathrm{LG}$ and $6.6 \mathrm{mmol} \cdot \mathrm{L}^{-1}$ of calcium) were determined in our laboratory in a previous study (Petit et al., 2011). At temperatures below $80^{\circ} \mathrm{C}, \beta-\mathrm{LG}$ denaturation is limited by the unfolding reaction, $\ln k^{\circ}$ $=98.4$, and $E_{\mathrm{A}}=304.6 \mathrm{~kJ} \cdot \mathrm{mol}^{-1}$, whereas at temperatures above $80^{\circ} \mathrm{C}, \beta$-LG denaturation is predominated by the aggregation mechanism, $\ln k^{\circ}=32.1$, and $E_{\mathrm{A}}=$ $110.9 \mathrm{~kJ} \cdot \mathrm{mol}^{-1}$, where $\ln k^{\circ}$ designates the logarithm of the denaturation frequency factor and $E_{\mathrm{A}}$ is the associated activation energy.

The heat treatment profiles used in our calculations mimicked those recorded by temperature monitoring during the heat treatment procedures. The temperature evolution in the samples was almost linear in 2 successive time ranges: after a fast, linear temperature increase from the initial temperature $\left(60^{\circ} \mathrm{C}\right)$ to the desired one, the sample temperature remained constant.

The times needed to heat the $\beta$-LG samples from $60^{\circ} \mathrm{C}$ to the holding temperatures were as follows: 15
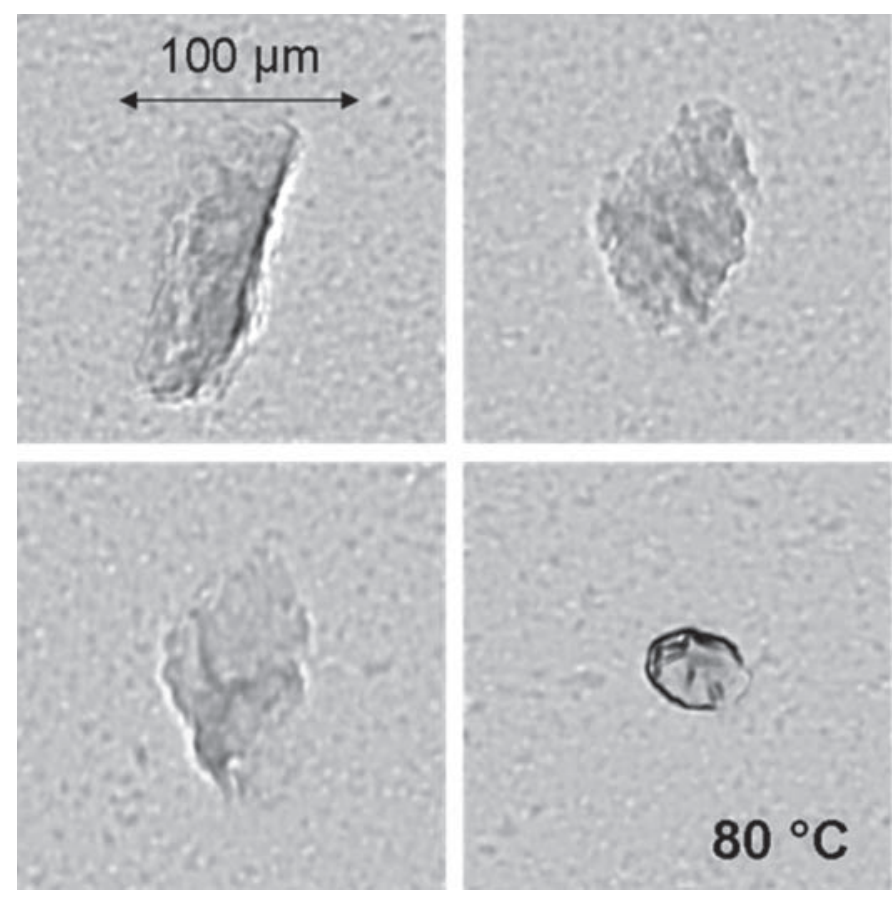

Figure 1. Appearance of aggregates in the presence of $\mathrm{N}$-ethylmaleimide (NEM; Sigma-Aldrich, St. Louis, MO) for various sampling times at $80^{\circ} \mathrm{C}$. The size scale is identical in all panels. $\mathrm{s}$ for $70^{\circ} \mathrm{C}, 30 \mathrm{~s}$ for $75^{\circ} \mathrm{C}, 45 \mathrm{~s}$ for $80^{\circ} \mathrm{C}, 50 \mathrm{~s}$ for $85^{\circ} \mathrm{C}$, $60 \mathrm{~s}$ for $90^{\circ} \mathrm{C}$, and $90 \mathrm{~s}$ for $95^{\circ} \mathrm{C}$. Heating rates for the selected holding temperatures ranged from 0.33 to $0.67^{\circ} \mathrm{C} \cdot \mathrm{s}^{-1}$.

\section{RESULTS}

The first part of this study presents the granulomorphometric method developed to identify $\beta$-LG aggregate binding interactions. This method was applied to determine the structure of $\beta-L G$ aggregates formed by heat treatments between 70 and $95^{\circ} \mathrm{C}$.

The second part of this work investigates the role of temperature in the mechanism of $\beta-\mathrm{LG}$ aggregation by following the evolution of the gray level in the granulomorphometric picture as well as the aggregate number and size in the different heat treatment experiments. These observations were related to calculations of the $\beta$-LG denaturation level to suggest an aggregation mechanism adapted to $\beta$-LG concentrates with a moderate calcium content.

\section{Use of Granulomorphometry for the Identification of Hydrophobic and Disulfide Bonds in $\beta$-LG Aggregates}

This section shows that the appearance of $\beta$-LG aggregates in granulomorphometric pictures could be linked to the binding interactions constituting their structure. An attempt was made to relate this structural information to the water-holding capacity of the aggregate.

Figure 1 displays granulomorphometric pictures obtained at $80^{\circ} \mathrm{C}$, illustrating the appearance of $\beta$-LG aggregates in the presence of NEM. Aggregates formed at temperatures less than or equal to $75^{\circ} \mathrm{C}$ were too small to be presented in this paper, whereas temperatures above $85^{\circ} \mathrm{C}$ were responsible for gelation of the $\beta$-LG solution, making granulomorphometric analysis irrelevant.

Aggregates formed in the presence of NEM are known to be almost exclusively composed of hydrophobic interactions (Xiong et al., 1993; Hoffmann and Van Mill, 1997) because NEM blocks the $\beta$-LG thiol function, preventing the formation of disulfide bonds between $\beta$-LG units by thiol oxidation or disulfide interchange. In Figure 1, the NEM-treated aggregates appear translucent (light gray) in the granulomorphometric pictures, which permitted us to state that hydrophobic aggregates had a translucent aspect in granulomorphometric analysis. It can be added that these hydrophobic aggregates had gray levels comparable with those of the picture background. Because the background calibration was performed on deionized 
water, this may indicate that a large amount of water was entrapped in the hydrophobic aggregates. In other words, the similar refractive indexes of water and the hydrophobic aggregates suggest that water has a high affinity for hydrophobic interactions (i.e., hydrophobic bonds have a high water-holding capacity).

This hypothesis was corroborated by performing additional granulomorphometric analyses on insoluble materials suspended in water. On one hand, particles that did not contain water appeared in black in the granulomorphometric pictures because they were opaque to incident light, owing to their refractive index being very different from that of water. Figure 2 illustrates this point with pictures of air bubbles and calcium chloride (which is known to be highly insoluble) suspended in deionized water.

In Figure 2, the granulomorphometric picture on the left shows that bubbles were accidentally pumped in together with the skim milk being analyzed, causing the presence of black disks. The circularity of these black particles was extremely high (very close to 1 ), undoubtedly corresponding to air bubbles. One should note that some bubbles had a white spot in the center, owing to the straight path of the incident light through the bubble axis of symmetry. The black appearance followed from the strong refraction of the incident light on the bubble surface: light rays out of the optical axis did not reach the acquisition camera.

In the picture on the right of Figure 2, calcium carbonate was also detected by granulomorphometry as black particles. This was related to its high insolubility. Indeed, almost no water molecules could enter the powder structure; thus, the calcium carbonate particles were expected to have a refractive index very different from that of the solvent. As in the case of air bubbles, light rays underwent a strong refraction at the solventparticle interface, so they did not reach the detector.

On the other hand, solids containing a certain water fraction had a refractive index closer to that of water: some areas of these particles also appeared in light gray in the granulomorphometric pictures, as illustrated in Figure 3, which presents pictures acquired in the laboratory in a side study dealing with the rehydration mechanisms of a phosphocaseinate powder. Particle dissolution was followed by evaluating the solvent entering the powder particles by granulomorphometry. The pictures in Figure 3 allowed us to compare the particle appearance in ethanol (left picture), in which phosphocaseinates are totally insoluble, and in water (right picture), in which dissolution takes place. For each solvent, the granulomorphometric pictures were acquired 5 min after powder addition.
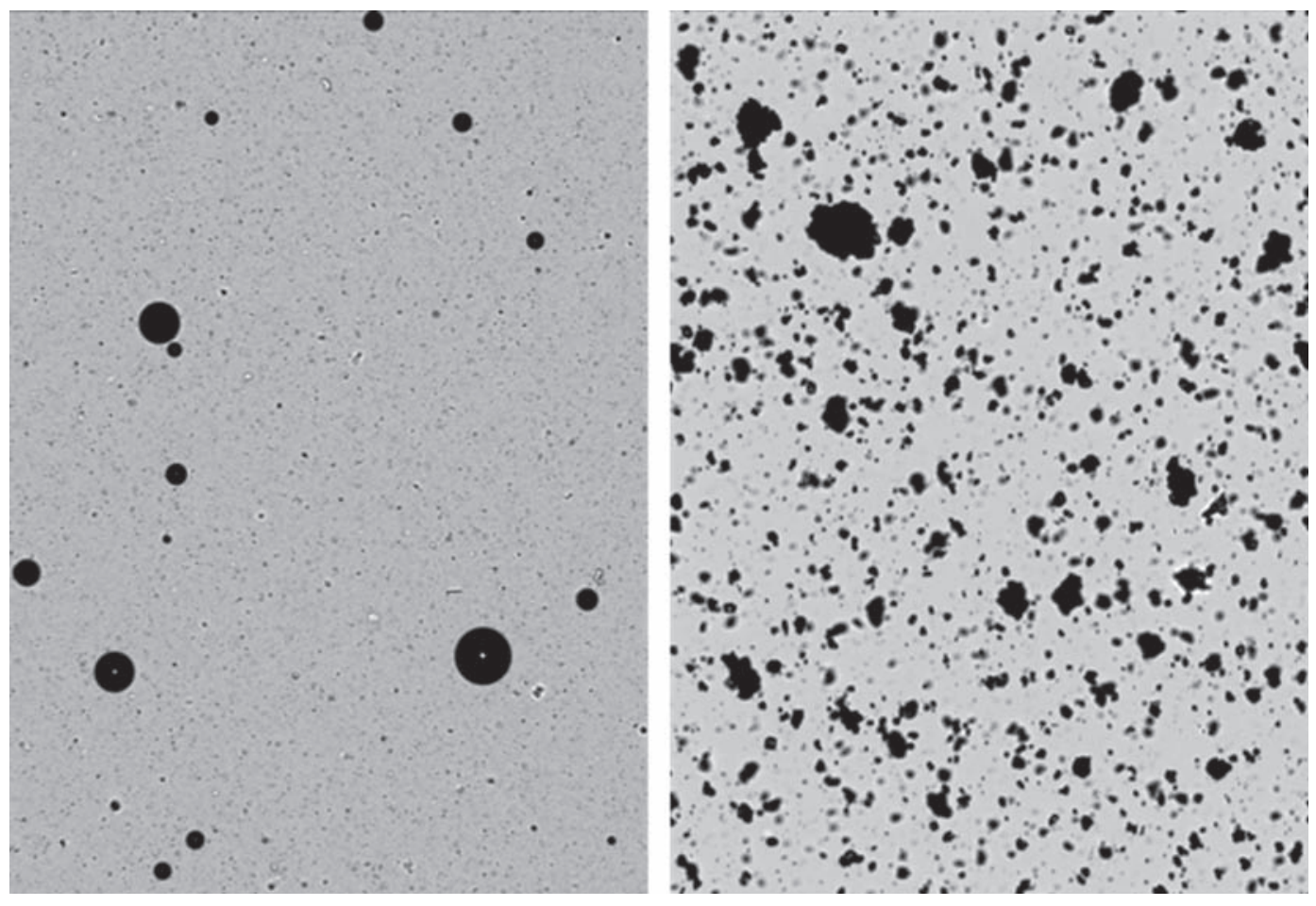

Figure 2. Left: Bubbles observed during the granulomorphometric analysis of a simulated skim milk. Right: Analysis of a $10 \mathrm{~g} \cdot \mathrm{L}^{-1}$ calcium carbonate suspension, carried out immediately after powder addition. Both panels are 1,280 $\mu \mathrm{m}$ wide. 

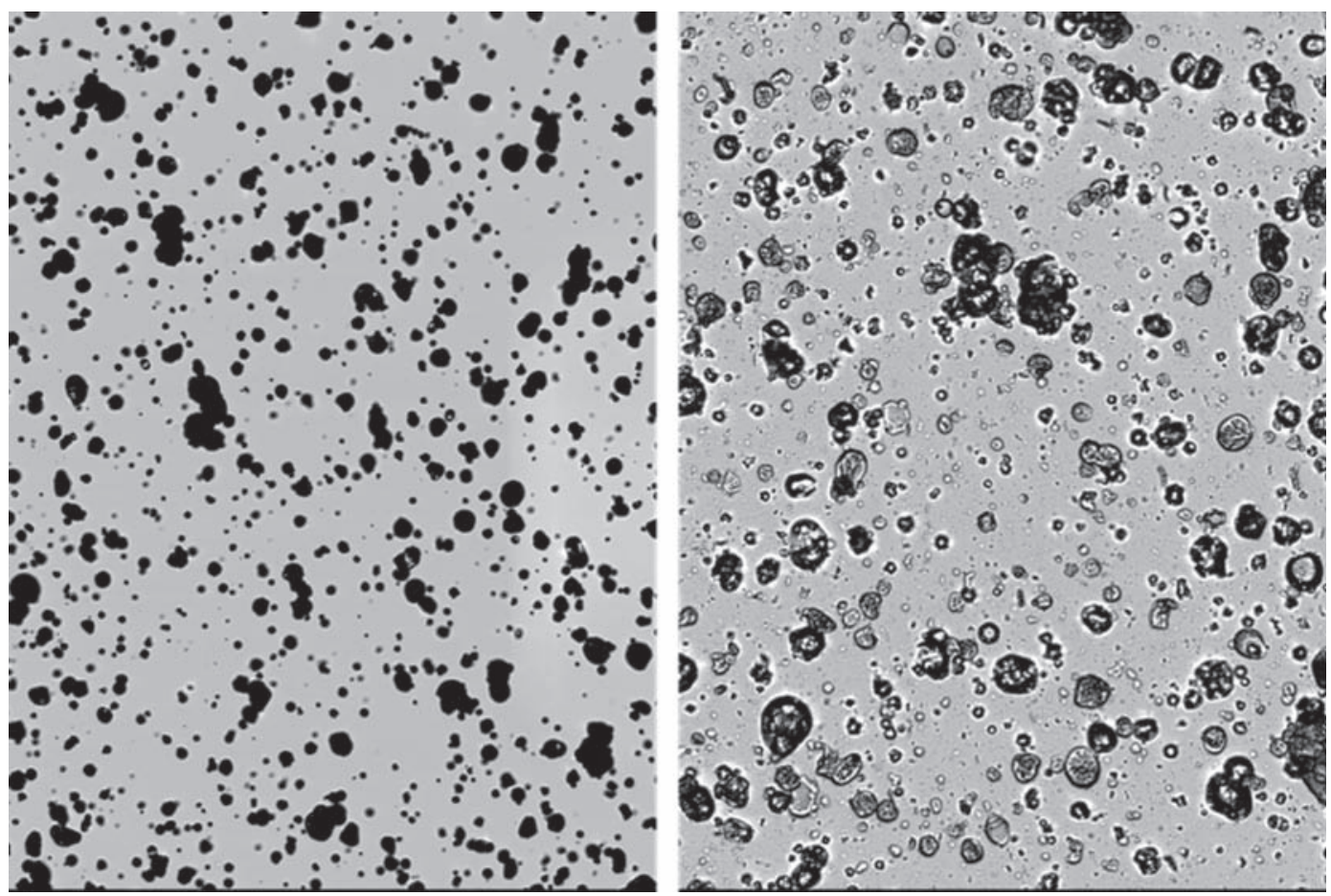

Figure 3. Left: Suspension of a phosphocaseinate powder in ethanol. Right: Suspension of the same phosphocaseinate powder in deionized water. Both panels are 1,280 $\mu \mathrm{m}$ wide. In both analyses, light calibration was performed on solvent [i.e., ethanol (left) or water (right)].

Powder particles appeared totally black in ethanol and ranged from light gray to black in water, which confirmed the difference in solubility between these solvents. From Figure 3, it is clear that soluble powder particles incorporate water during the rehydration process, which results in the appearance of light gray areas inside the particles. This did not occur in ethanol, in which phosphocaseinates are insoluble and which is thus impermeable to the entrance of the solvent. It can be deduced from these observations that the granulomorphometric gray level of a particle is linked to its solvent affinity.

Hence, the gray level of aggregates constituted an indicator of water-holding capacity: the lighter the $\beta-\mathrm{LG}$ aggregates appeared in the granulomorphometric pictures, the higher was their water fraction. It could be deduced that the translucency of hydrophobic aggregates in the granulomorphometric pictures was indicative that they had a good water-holding capacity.

After having characterized the hydrophobic aggregates by granulomorphometry, we showed the ability of this analytical method to discriminate between hydrophobic and disulfide bonds in $\beta$-LG aggregates formed without a thiol-blocking agent. Figure 4 displays the appearance of the aggregate at temperatures ranging from 80 to $95^{\circ} \mathrm{C}$ after different heating times in solutions free of NEM.
Figure 4 shows that the aggregates formed in the absence of NEM had a different appearance than did purely hydrophobic aggregates (observed in NEMtreated $\beta$-LG solutions, as in Figure 1). In fact, aggregates had both dark and translucent areas across the entire temperature range. The translucent areas corresponded to hydrophobic interactions, such as in the case of the NEM-treated $\beta-\mathrm{LG}$ solutions, whereas dark areas indicated the presence of another kind of binding interaction: disulfide bonds, which are known to take part in $\beta$-LG aggregation mechanisms.

A comparison of Figures 1 and 4 showed that the aggregates formed in NEM-treated solutions had a more homogeneous aspect and a more spherical structure than those produced in the absence of NEM. This could be explained by the competition between hydrophobic and disulfide bonds during the $\beta$-LG heat aggregation mechanism in the absence of NEM. Indeed, at temperatures below $85^{\circ} \mathrm{C}$, the competition between these 2 interaction binding types led to the formation of either fully hydrophobic or fully covalent aggregates, corresponding, respectively, to the translucent and dark particles in the granulomorphometric pictures in Figure 4.

At temperatures above $90^{\circ} \mathrm{C}$ (Figure 4), the aggregation mechanism appeared to change: the majority of aggregates contained both opaque and translucent 


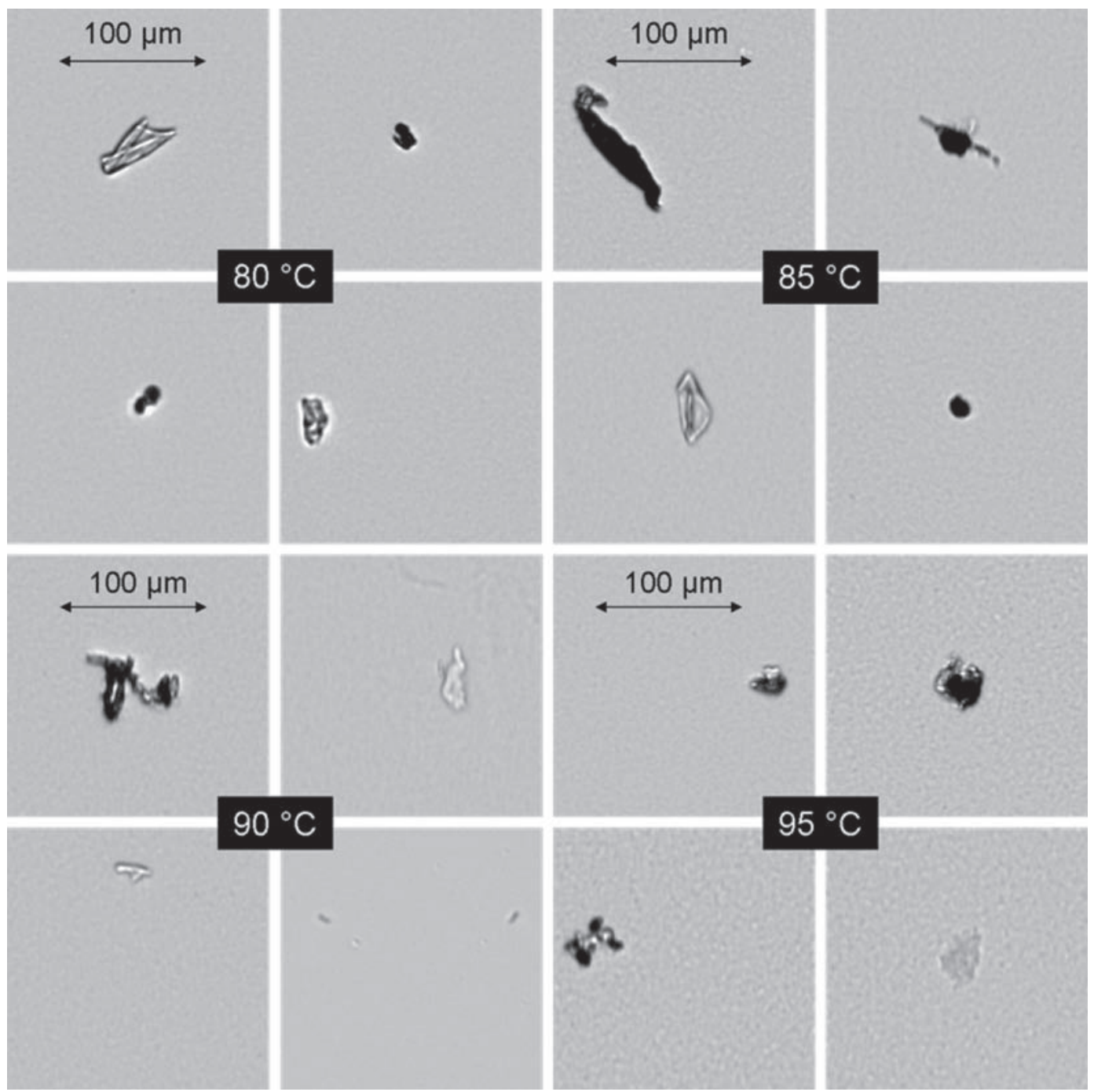

Figure 4. Appearance of aggregates in $\beta$-LG concentrates at 80 (top left), 85 (top right), 90 (bottom left), and $95^{\circ} \mathrm{C}$ (bottom right). The size scale is the same in all panels.

areas, which was indicative of a more complex, hybrid structure. Hydrophobic and disulfide interactions were consistently segregated in different locations of the $\beta-\mathrm{LG}$ aggregate, validating the hypothesis of competition between hydrophobic and disulfide bonds across the entire temperature range.

Finally, the shape of the aggregates appeared to follow from this binding interaction competition. As shown in Figure 1, aggregates found in NEM-treated solutions after heat treatment had a rather spherical shape, owing to the random location of hydrophobic bonds. In contrast, Figure 4 displays aggregates formed in the absence of NEM, which seemed to be composed of small stick-shaped dark or translucent aggregates placed side by side.
Furthermore, the fact that aggregates at temperatures above $85^{\circ} \mathrm{C}$ were larger and contained more opaque areas was a sign that the aggregation mechanism changed around $85^{\circ} \mathrm{C}$. In brief, at temperatures below $85^{\circ} \mathrm{C}$, hydrophobic and disulfide aggregates did not associate, whereas at temperatures above $90^{\circ} \mathrm{C}$, small aggregates of each type adhered to form large aggregates.

It can be noted that the picture background became more granular as the holding temperature increased, which denotes an increase in the number of $\beta-\mathrm{LG}$ aggregates with an increase in temperature. The light gray spots observed in the picture background most certainly correspond to small aggregates located near the walls of the analytical flow cell, which explains the fuzziness of the granulomorphometric picture background. 


\section{Role of Temperature in $\beta$-LG Aggregation Mechanisms}

The evolution of granulometric parameters (size and number) of the $\beta$-LG aggregates during the different heat treatments was monitored to understand how hydrophobic and disulfide bonds contributed to the formation and shaping of aggregates as a function of temperature. We were able to calculate the evolution of the $\beta$-LG denaturation level during the heat treatment procedures to help interpret the granulomorphometric measurements. This approach led us to propose an aggregation mechanism for $\beta$-LG concentrates with a moderate calcium content in the temperature range of 70 to $95^{\circ} \mathrm{C}$, explaining the formation of the $\beta$-LG aggregate structures observed by granulomorphometry.
Calculation of the Denaturation Level as a Function of the Heat Profile. In this subsection, we present the calculations performed to assess the evolution of $\beta$-LG denaturation during the heat treatment procedures. This is useful for interpreting the granulomorphometric analyses.

Figure 5 shows the results obtained for holding times of less than $30 \mathrm{~min}$ at the 6 experimental temperatures in the $\beta$-LG concentrate without a thiol-blocking agent. The denaturation level represents the proportion of $\beta-L G$ proteins that were irreversibly denatured (i.e., converted to aggregates).

It is obvious in Figure 5 that the denaturation level increased strongly with temperature and moderately with time. Indeed, the time needed to denature $95 \%$ of the $\beta$-LG proteins was less than $5 \mathrm{~min}$ at the highest

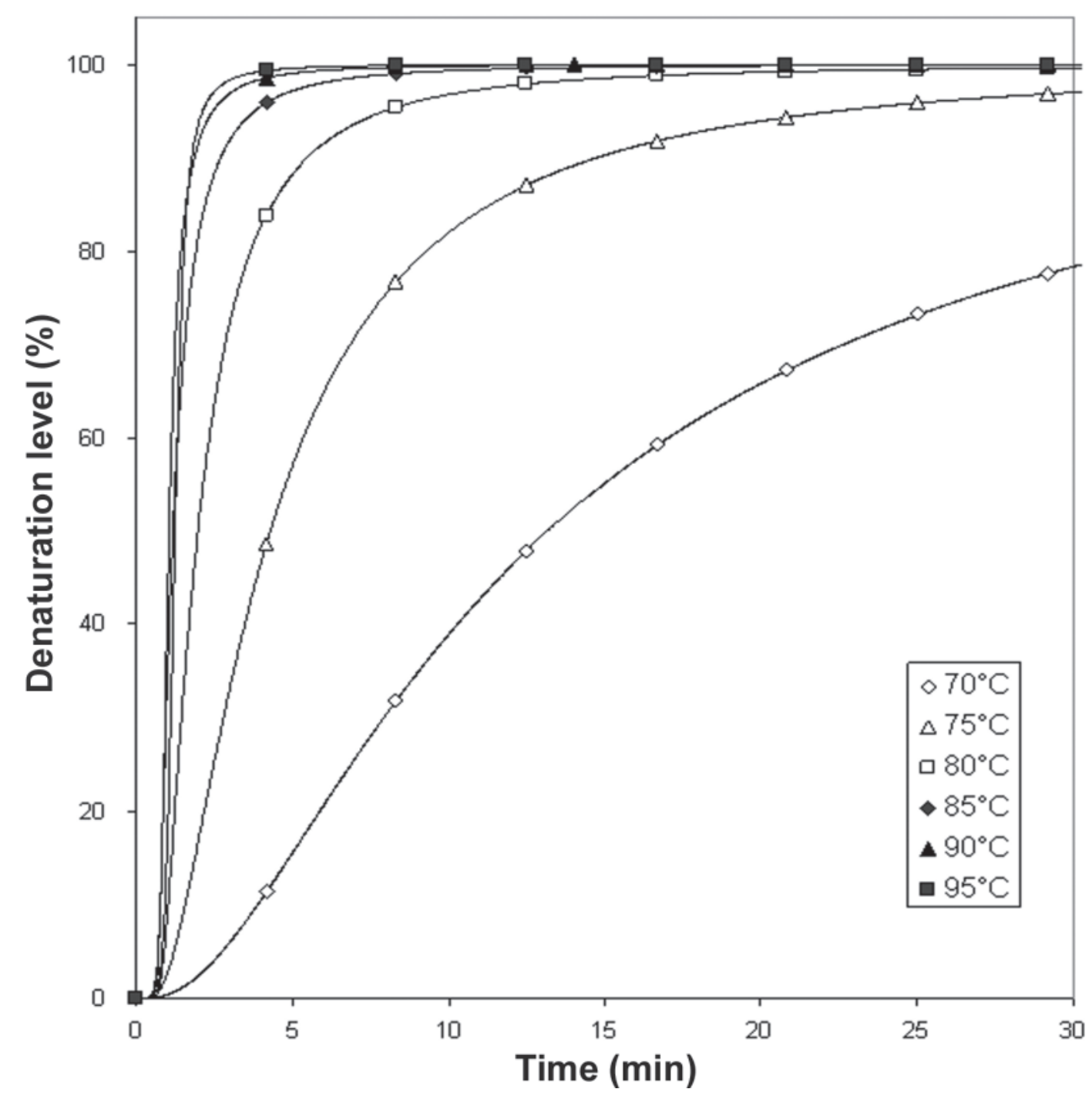

Figure 5. Calculation of $\beta$-LG denaturation during the heat treatments performed. 




Figure 6. Temperature influence on the gray level of granulomorphometric pictures acquired with and without $N$-ethylmaleimide (NEM; Sigma-Aldrich, St. Louis, MO).

temperatures (above $85^{\circ} \mathrm{C}$ ), whereas at 70 or $75^{\circ} \mathrm{C}$, more than 20 min was required (data not shown in Figure 5), and at $80^{\circ} \mathrm{C}$, this time was reduced to approximately 10 min. Regarding the time effect, $\beta-\mathrm{LG}$ denaturation was faster in the first minutes of the heating experiment: at temperatures greater than $75^{\circ} \mathrm{C}$, a $50 \%$ denaturation level was reached in less than $5 \mathrm{~min}$ of heat treatment. This indicates that most of the $\beta$-LG molecules were denatured in the samples free of NEM, except for heat treatment times of less than $30 \mathrm{~min}$ at $70^{\circ} \mathrm{C}$ and $10 \mathrm{~min}$ at $75^{\circ} \mathrm{C}$.

Regarding the evolution of denaturation in NEMtreated samples, the associated denaturation rates were not determined, principally because of the tendency of NEM-treated $\beta$-LG solutions to gelate even at low temperatures and short heating times. Nevertheless, it was expected, based on the literature, that $\beta$-LG denaturation rates would be drastically reduced by NEM addition because NEM blocks the $\beta$-LG thiol group (Xiong et al., 1993; Hoffmann and Van Mill, 1997), precluding its irreversible denaturation via thiol group oxidation or disulfide interchange. This point permits us to state that the NEM-treated $\beta$-LG solutions had lower denaturation levels than did the raw $\beta$-LG solutions for all tested temperatures.
Influence of Temperature on $\beta-L G$ Aggregate Size and Number. The gray level in the picture background was calculated by means of Image $\mathrm{J}$ freeware for the first granulomorphometric analysis of each sample (16 pictures). The results are reported in Figure 6.

Note that small gray level discrepancies were apparent between samples at different temperatures and holding times: all gray levels were between 195 and 198 . Before each analysis, light calibration was performed by adjusting the gray level of deionized water to 200 . So, the contribution of the aggregate to the overall gray level was significant enough to allow aggregation monitoring.

The gray level of $\beta$-LG solutions without NEM decreased from 70 to $80^{\circ} \mathrm{C}$, which corresponded to a darkening of the picture background, and it remained constant around 195.5 at temperatures above $85^{\circ} \mathrm{C}$. The similar results acquired at 1- and 4-h sampling times proved that no further aggregation occurred after a 1-h heat treatment. This is easily understandable, given that the denaturation level, which was already close to $100 \%$, did not vary significantly after a 60 -min heat treatment (data not shown in Figure 5).

The gray level of the picture background decreased at temperatures below $80^{\circ} \mathrm{C}$, and its stable value at 
temperatures above $85^{\circ} \mathrm{C}$ could be interpreted as a consequence of the increase in aggregation level with temperature, resulting in an increase in the growth and number of aggregates. On one hand, the presence of aggregates reduced the light transmitted through the sample. As the denaturation and aggregation processes were strongly enhanced by the temperature increase, the picture background darkened from 70 to $80^{\circ} \mathrm{C}$, which is expressed in Figure 6 by a decrease in the gray level. On the other hand, most of the aggregates appeared lighter than the background in the granulomorphometric pictures (see Figure 4); this phenomenon tended to increase the overall gray level in the picture. As aggregates began to be apparent around $85^{\circ} \mathrm{C}$, the background darkening and the appearance of small, light aggregates compensated in such a way that the gray level stabilized at around 195.5.

In the presence of a thiol-blocking agent, the $\beta$-LG solutions adopted a similar behavior, but the temperature range was slightly different: the darkening of the picture background attributable to aggregate formation reduced the gray level at temperatures between 70 and $75^{\circ} \mathrm{C}$, whereas the appearance of light aggregates, which were noticeable from $80^{\circ} \mathrm{C}$, tended to bring the gray level back to its initial value of 197.5 at $85^{\circ} \mathrm{C}$. This confirms that hydrophobic aggregation was highly favored in the presence of a thiol-blocking agent such as NEM, in comparison with the raw $\beta$-LG solution.

The number of aggregates was equally monitored in these heat treatment experiments, and its temporal evolution at different temperatures is presented in Figure 7 . The number of aggregates displayed in this figure corresponds to the total number of aggregates detected by the image analysis software on the 16 pictures of a single granulomorphometric analysis. The results presented were averaged on the basis of 5 granulomorphometric analyses.

The results presented in Figure 7 suggest that the $\beta$-LG aggregation mechanism changed between 85 and $90^{\circ} \mathrm{C}$. The aggregation mechanism below $85^{\circ} \mathrm{C}$ was characterized by a small number of aggregates after a 4-h heat treatment, that is, fewer than 1,000 aggregates at $70^{\circ} \mathrm{C}$ and between 1,000 and 1,500 particles for other temperatures below $85^{\circ} \mathrm{C}$. In this temperature range, the great majority of aggregates were formed after only a 10-min heat treatment (approximately 600 aggregates at $70^{\circ} \mathrm{C}$, and between 1,000 and 1,500 particles for the other temperatures), owing to the maximal value of the $\beta-L G$ denaturation rate in the first moments of the heat treatment (see Figure 5), which resulted in a high availability of molten globule $\beta$-LG for disulfide aggregation. After a few minutes (from $10 \mathrm{~min}$ to $1 \mathrm{~h}$, depending on the temperature), $\beta$-LG denaturation was almost complete and the denaturation rate declined because of the lack of native $\beta$-LG. From that time on, the availability of molten globule $\beta$-LG was strongly reduced and most of the newly formed aggregates were too small to be detected by granulomorphometry (their diameter was expected to be considerably less than the pixel scale of $0.38 \mu \mathrm{m})$. This may explain why the measured number of aggregates increased slightly until the end of the heat treatment.

In addition, the large aggregates obtained after long heat treatment times (see Figure 4) were expected to proceed from the hydrophobic agglomeration of small aggregates rather than from aggregate growth by reaction with denatured $\beta$-LG (Hongsprabhas and Barbut, 1997; Ikeda, 2003) because to take place, the latter mechanism requires a sufficient amount of denatured $\beta$-LG and thus cannot occur in solutions in which the $\beta$-LG denaturation level is already close to $100 \%$. Thus, we deduced that the agglomeration rate of small aggregates by hydrophobic interactions was very low at temperatures below $85^{\circ} \mathrm{C}$ in static conditions.

At temperatures above $90^{\circ} \mathrm{C}, \beta$-LG denaturation was so enhanced that all the native $\beta$-LG were denatured in approximately $1 \mathrm{~min}$ (see Figure 5). Aggregation rates were drastically increased as well, as evidenced by the very high particle numbers recorded at 90 and $95^{\circ} \mathrm{C}$ after $4 \mathrm{~h}$ of heat treatment: 3,500 and 12,000 aggregates, respectively. The 1,500 particles measured in the 10-min sample were comparable with the value found at temperatures below $85^{\circ} \mathrm{C}$, suggesting that the same mechanism acted in the first moments of the heat treatment, whatever the temperature; it dealt with aggregate growth by the addition of denatured $\beta$-LG. The large increase in aggregate numbers, which was observed only at temperatures above $90^{\circ} \mathrm{C}$, permitted us to add that the formation of large aggregates by the agglomeration of small aggregates was favored at temperatures above $90^{\circ} \mathrm{C}$.

Regarding the results obtained in the presence of NEM (data not shown), we found that the aggregate number at temperatures below $75^{\circ} \mathrm{C}$ was less in NEMtreated solutions than in raw $\beta$-LG solutions. This suggests that the $\beta-\mathrm{LG}$ denaturation rate was decreased by the addition of a thiol-blocking agent, and it confirms that aggregation in the first moments of the heat treatment was driven by disulfide interactions, provided that the $\beta$-LG thiol function was available.

In the presence of NEM, the aggregate numbers became very important at $80^{\circ} \mathrm{C}$ (approximately equal to 100,000 particles at the end of the heat treatment), indicating a marked increase in the rate of hydrophobic aggregation. It equally indicated the high gelation potential of NEM-treated solutions, which was perceptible in our experiments from the 10-min heat treatment at $85^{\circ} \mathrm{C}$. It could be deduced from these 


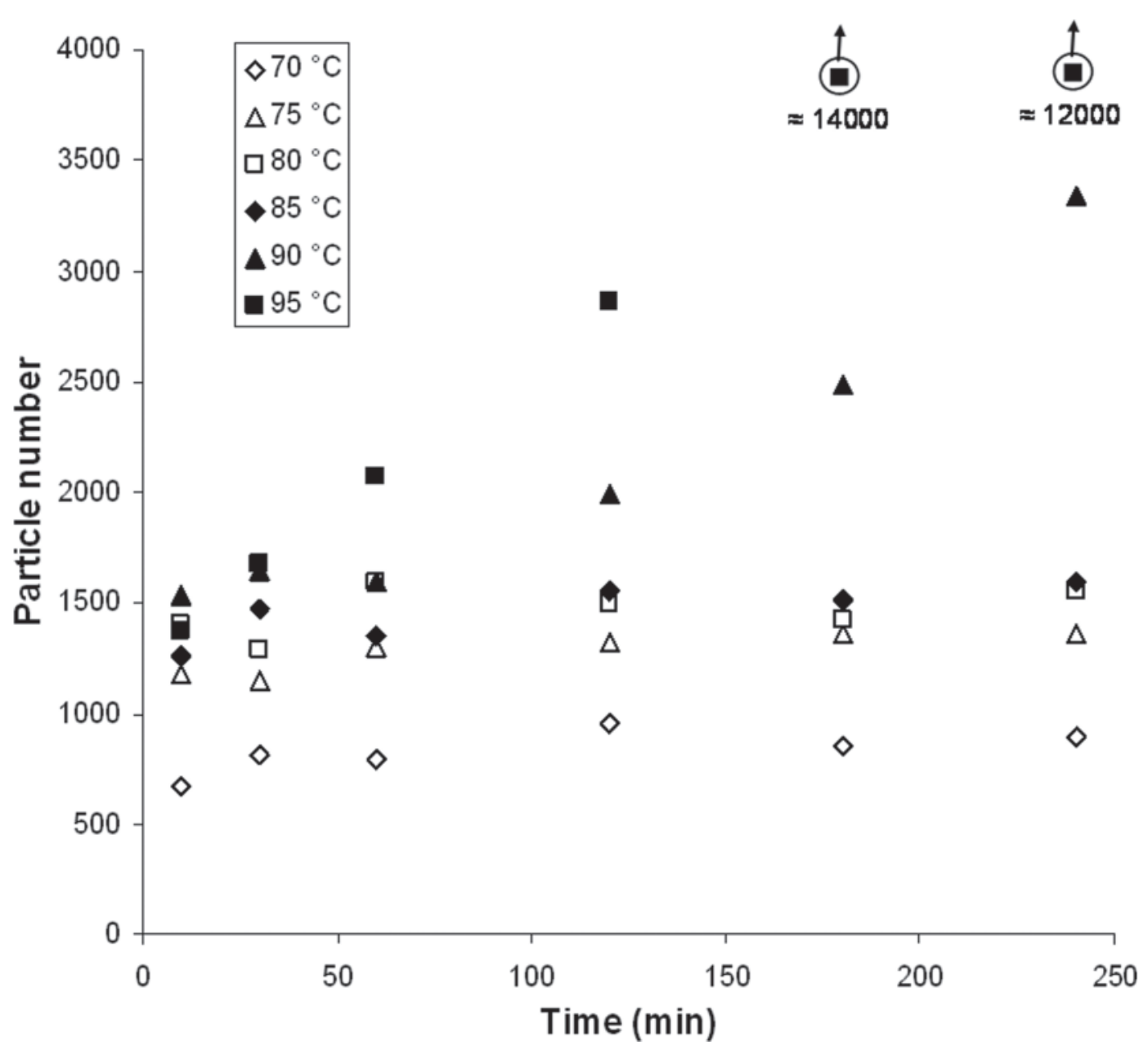

Figure 7. Temperature influence on the temporal evolution of the mean number of aggregates.

observations that the gelation temperature of the NEM-treated $\beta$-LG solution must have been between 80 and $85^{\circ} \mathrm{C}$.

Last, in Figure 8 we report the mean aggregate sizes obtained in $\beta$-LG concentrates not treated with NEM. As indicated previously, the mean aggregate size considered here refers to the average area diameter in 5 granulomorphometric analyses.

The granulomorphometric analyses performed indicate that the aggregate size was quite affected by temperature: measured particle diameters were higher between 70 and $85^{\circ} \mathrm{C}$ than for temperatures greater than $90^{\circ} \mathrm{C}$. First, this can be explained by the lower aggregate number obtained at temperatures below $85^{\circ} \mathrm{C}$. In fact, a significant fraction of aggregates formed at a low temperature were expected to be too small to be detected in granulomorphometry (less than the spatial resolution of the granulomorphometer: $0.38 \mu \mathrm{m}$ ), which tends to increase the measured aggregate mean diameter at temperatures less than $85^{\circ} \mathrm{C}$.
The temporal variation in the aggregate size reinforces this interpretation. At all temperatures, the $\mathrm{D}_{50}$ globally decreased with increasing sampling time, corroborating the previously stated aggregation mechanism. Indeed, in the first moments, denaturation was fast and led to the formation of numerous large aggregates, which corresponded to the high aggregate diameters (from 4 to $8 \mu \mathrm{m}$, depending on the temperature) obtained with the 10-min heat treatment. The denaturation was then slowed by the rarefaction of native $\beta-\mathrm{LG}$, and the aggregation rate was also reduced. The newly formed aggregates had small diameters, owing to the few denatured $\beta$-LG available for aggregation, which decreased the measured aggregate size. Finally, the last step in the aggregation mechanism consisted of the agglomeration of already formed aggregates because 100\% $\beta$-LG denaturation was already achieved. In this step, the aggregate size was expected to increase again, which was observed from the 3 -h sampling times, particularly at the highest temperatures. 


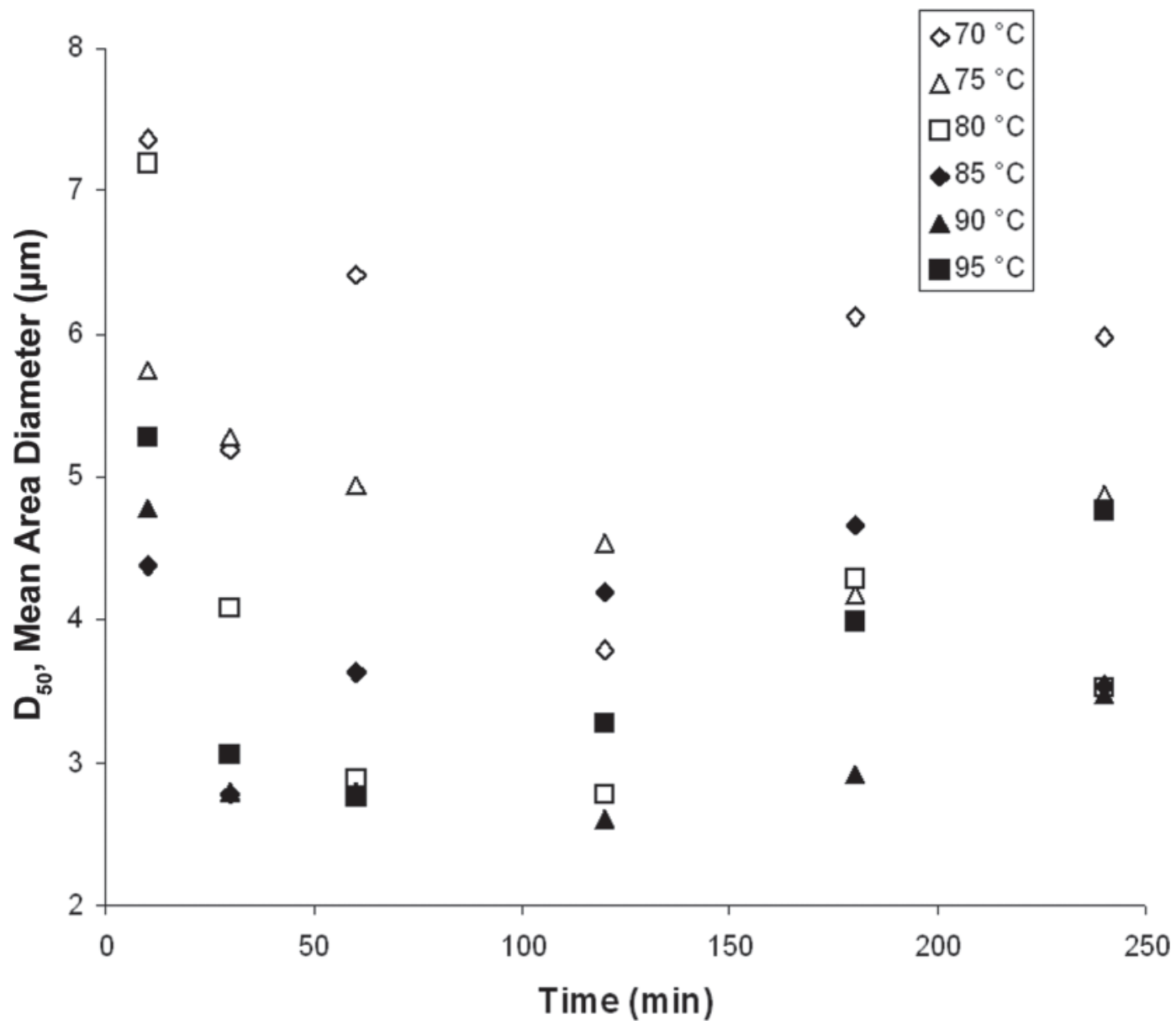

Figure 8. Temperature influence on the temporal evolution of the mean diameter of aggregates.

\section{DISCUSSION}

Finally, our aim was to gather the main findings of this work and compare them with literature studies to show how granulomorphometry, as a complementary technique to microscopy, might provide additional information on the properties of aggregates and improve the current understanding of $\beta$-LG aggregation mechanisms.

The first part of this work dealt with identifying by granulomorphometry the binding interactions responsible for $\beta$-LG aggregation. The use of a thiol-blocking agent (NEM) allowed us to relate hydrophobic interactions to aggregate translucency in the granulomorphometric pictures. As a consequence, we stated that opaque aggregates were mainly constituted from disulfide interactions. These conclusions disagree with microscopic or direct observations of $\beta-\mathrm{LG}$ aggregates in gels (Barbut, 1995a) and prevent the direct comparison of granulomorphometric and microscopic results. Furthermore, aggregate translucency in granulomorphometry was correlated with a high level of retained water, and we deduced that hydrophobic interactions induced a better water-holding capacity than did disulfide bonds. This contradicts literature studies dealing with free water (water released by gel squeezing or centrifugation), in which it has been established that finely stranded gels (formed mainly by disulfide interactions) are more prone to water release than are hydrophobic gels (Lupano et al., 1992; Spiegel, 1999). Nevertheless, some authors (Hongsprabhas and Barbut, 1997; Clare et al., 2007) have shown that calcium-enriched or low-temperature gels (known to be composed mainly of hydrophobic bonds) are able to retain a higher amount of water in the form of bound water (water that cannot be removed by squeezing or centrifugation). The following approach is in accordance with our observations. Thus, granulomorphometry allowed us to evaluate the presence of water in $\beta-L G$ aggregates qualitatively, but this technique seemed unable to differentiate between free or bound water fractions. 
The second part of this paper was devoted to applying granulomorphometry to the investigation of the aggregation mechanisms occurring in the temperature range from 70 to $95^{\circ} \mathrm{C}$. As reported in numerous papers (Barbut, 1995a; Hongsprabhas and Barbut, 1997; De Wit, 2009; Nicolai et al., 2011), we found that hydrophobic aggregates were more spherical and compact than were disulfide ones (compare Figures 1 and 4). Furthermore, the presence of disulfide bonds within $\beta$-LG aggregates is known to reduce their size. In our study, more small aggregates were observed at higher temperatures (see Figure 8), where covalent interactions are expected to be favored (De Wit, 2009). Regarding aggregate shapes, Nicolai et al. (2011) reported in their recent review that the shape of $\beta-\mathrm{LG}$ aggregates is extremely dependent on the $\mathrm{pH}$ value: they form long, rigid strands at $\mathrm{pH}$ 2.0 , spheres at $\mathrm{pH} 5.8$, and small curved strands at $\mathrm{pH}$ 7.0. This is consistent with our observations performed in a $\beta$-LG concentrate at $\mathrm{pH}$ 6.8: the $\beta-\mathrm{LG}$ aggregates adopted shapes ranging from spheres to curved sticks, depending on the temperature, as also shown in the work of Simmons et al. (2007). High-temperature aggregates (termed hybrid aggregates in our study) seemed to be formed by the association of small stick-shaped (see the upper right quadrant at $85^{\circ} \mathrm{C}$ in Figure 4) or spherical (compare the left upper quadrant at $90^{\circ} \mathrm{C}$ and the lower left quadrant at $95^{\circ} \mathrm{C}$ in Figure 4) aggregates, which coincides with the mechanisms reported by Barbut (1995b) and Simmons et al. (2007). Finally, the aggregation mechanism described in our study joins the model of Sawyer (1968): in a first step, primary aggregates are formed by disulfide bonds as a consequence of $\beta-L G$ denaturation, and in a second step, these primary aggregates adhere under the influence of hydrophobic interactions, which lead to large aggregates with a hybrid structure. Our study permits us to emphasize the role of ionic strength and calcium in $\beta-\mathrm{LG}$ aggregation. In fact, the model of De Wit (2009), which is applicable for low ionic strengths, does not apply for our $\beta$-LG concentrate with a moderate calcium content because both interaction types were found in the temperature range from 70 to $95^{\circ} \mathrm{C}$.

\section{CONCLUSIONS}

This study demonstrates that granulomorphometry has a good ability to depict aggregation phenomena occurring in $\beta$-LG solutions. This analytical technique was applied to study the $\beta$-LG aggregation mechanisms and their dependence on temperature between 70 and $90^{\circ} \mathrm{C}$. Six heat-denaturation procedures were performed on $\beta$-LG concentrates at holding temperatures of 70 to $95^{\circ} \mathrm{C}$, and aggregate formation was monitored by granulomorphometric measurements at holding times ranging from $10 \mathrm{~min}$ to $4 \mathrm{~h}$. Two categories of results were deduced from this experimental set: the binding interactions involved in aggregate formation were identified, and the influence of temperature on the aggregation mechanisms was clarified. Below $85^{\circ} \mathrm{C}$, aggregates were either fully hydrophobic or fully covalent, whereas above $90^{\circ} \mathrm{C}$, aggregates contained both kinds of interactions segregated in different locations. We suggested that disulfide and hydrophobic binding compete for $\beta-\mathrm{LG}$ aggregation and that the aggregation mechanism changes between 85 and $90^{\circ} \mathrm{C}$. Across the entire temperature range, $\beta$-LG denaturation was initially fast, which resulted in a large availability of molten globule $\beta$-LG for aggregation by disulfide bonds. The $\beta$-LG denaturation was then completed between $10 \mathrm{~min}$ and 1 $\mathrm{h}$, depending on the temperature, and the denaturation rate declined because of the lack of native $\beta$-LG. A second aggregation mechanism became preponderant after this denaturation step, namely, the agglomeration of small aggregates by hydrophobic interactions, which resulted in the formation of large aggregates containing both hydrophobic and disulfide bonds.

\section{ACKNOWLEDGMENTS}

This work was carried out within the framework of the Globule project (No. ANR-08-ALIA-08). The granulomorphometer apparatus was purchased within the framework of an ARCIR program (European Regional Development Fund Nos. 09310243 and 03310 241). The authors thank their partners in the Globule project and especially acknowledge the technical staff of Occhio (Angleur, Belgium).

\section{REFERENCES}

Barbut, S. 1995a. Effect of sodium level on the microstructure and texture of whey protein isolate gels. Food Res. Int. 28:437-443.

Barbut, S. 1995b. Effects of calcium level on the structure of preheated whey protein isolate gels. Food Sci. Technol. 28:598-603.

Benning, R., H. Petermeier, A. Delgado, J. Hinrichs, U. Kulozik, and T. Becker. 2003. Process design for improved fouling behaviour in dairy heat exchangers using a hybrid modelling approach. Trans. Inst. Chem. Eng. C Food Bioprod. Process. 81:266-274.

Blanpain-Avet, P., A. Hédoux, Y. Guinet, L. Paccou, J. Petit, T. Six, and G. Delaplace. 2012. Analysis by Raman spectroscopy of the conformational structure of whey proteins constituting fouling deposits during the processing in a heat exchanger. J. Food Eng. 110:86-94.

Briggs, D. R., and R. Hull. 1945. Studies on protein denaturation. I. Electrophoretic study kinetics at neutrality of heat denaturation of 3-lactoglobulin. J. Am. Chem. Soc. 67:2007-2014.

Clare, D. A., S. J. Lillard, S. R. Ramsey, P. M. Amato, and C. R. Daubert. 2007. Calcium effects on the functionality of a modified whey protein ingredient. J. Agric. Food Chem. 55:10932-10940.

De La Fuente, M. A., H. Singh, and H. Hemar. 2002. Recent advances in the characterisation of heat-induced aggregates and intermediates of whey proteins. Trends Food Sci. Technol. 13:262-274. 
Delplace, F., J. C. Leuliet, and D. Levieux. 1997. A reaction engineering approach to the analysis of fouling by whey proteins of a sixchannels-per-pass plate heat exchanger. J. Food Eng. 34:91-108.

De Wit, J. N. 2009. Thermal behaviour of bovine $\beta$-lactoglobulin at temperatures up to $150^{\circ} \mathrm{C}$. A review. Trends Food Sci. Technol. $20: 27-34$.

Fryer, P. J., G. K. Christian, and W. Liu. 2006. How hygiene happens: Physics and chemistry of cleaning. Int. J. Dairy Technol. 59:76-84.

Gault, P., and J. Fauquant. 1992. Heat-induced gelation of $\beta$-lactoglobulin-Influence of $\mathrm{pH}$, ionic-strength and presence of other whey proteins. Dairy Sci. Technol. 72:491-510.

Georgiadis, M. C., G. E. Rotstein, and S. Macchietto. 1998. Modelling and simulation of complex plate heat exchanger arrangements under milk fouling. Comput. Chem. Eng. 22(Suppl.):331-338.

Grijspeerdt, K., L. Mortier, J. De Block, and R. Van Renterghem. 2004. Applications of modelling to optimise ultra high temperature milk heat exchangers with respect to fouling. Food Contr. 15:117-130.

Havea, P., A. J. Carr, and L. K. Creamer. 2004. The roles of disulfide and non-covalent bonding in the functional properties of heat-induced whey protein gels. J. Dairy Res. 71:330-339.

Havea, P., H. Singh, and L. K. Creamer. 2001. Characterization of heat-induced aggregates of $\beta$-lactoglobulin, $\alpha$-lactalbumin and bovine serum albumin in a whey protein concentrate environment. J. Dairy Res. 68:483-497.

Hoffmann, M. A. M., and P. J. J. M. Van Mill. 1997. Heat-induced aggregation of $\beta$-lactoglobulin: The role of the free thiol group and disulphide bonds. J. Agric. Food Chem. 45:2942-2948.

Hongsprabhas, P., and S. Barbut. 1997. Structure-forming processes in $\mathrm{Ca}^{2+}$-induced whey protein isolate cold gelation. Int. Dairy J. 7:827-834

Ikeda, S. 2003. Heat-induced gelation of whey proteins observed by rheology, atomic force microscopy, and Raman scattering spectroscopy. Food Hydrocoll. 17:399-406.

Ikeda, S., and E. C. Y. Li-Chan. 2004. Raman spectroscopy of heatinduced fine-stranded and particulate $\beta$-lactoglobulin gels. Food Hydrocoll. 18:489-498.

Jun, S., and V. M. Puri. 2007. Plate heat exchanger: Thermal and fouling analysis. Pages 417-430 in Computational Fluid Dynamics in Food Processing. D.-W. Sun, ed. CRC Press, New York, NY.

Labouré, H., E. Cases, and P. Cayot. 2004. Heat induced $\beta$-lactoglobulin polymerization: Role of change in medium permittivity. Food Chem. 85:399-406.

Lalande, M., F. René, and J.-P. Tissier. 1989. Fouling and its control in heat exchangers in the dairy industry. Biofouling 1:233-250.

Linmark-Mansson, H., A. Timgren, G. Alden, and M. Paulsson. 2005. Two-dimensional gel electrophoresis of proteins and peptides in bovine milk. Int. Dairy J. 15:111-121.

Lupano, C. E., E. Dumay, and J. C. Cheftel. 1992. Gelling properties of whey-protein isolate-Influence of calcium removal by dialysis or diafiltration at acid and neutral pH. Int. J. Food Sci. Technol. $27: 615-628$

Mounsey, J. S., and B. T. O'Kennedy. 2007. Conditions limiting the influence of thiol-disulphide interchange reactions on the heatinduced aggregation kinetics of $\beta$-lactoglobulin. Int. Dairy J. 17:1034-1042.

Mulvihill, D. M., and M. Donovan. 1987. Whey proteins and their thermal denaturation-A review. Irish J. Food Sci. Technol. 11:43-75.

Nicolai, T., M. Britten, and C. Schmitt. 2011. $\beta$-Lactoglobulin and WPI aggregates: Formation, structure and applications. Food Hydrocoll. 25:1945-1962.

Nielsen, B. T., H. Singh, and J. M. Latham. 1995. Aggregation of bovine $\beta$-lactoglobulin $\mathrm{A}$ and $\mathrm{B}$ on heating at $75^{\circ} \mathrm{C}$. Int. Dairy J. $6: 519-527$

Perez, O. E., and A. M. R. Pilosof. 2004. Pulsed electric effects on the molecular structure and gelation of $\beta$-lactoglobulin concentrate and egg white. Food Res. Int. 37:102-110.

Petit, J., A.-L. Herbig, A. Moreau, and G. Delaplace. 2011. Calcium influence on $\beta$-lactoglobulin denaturation kinetic rates: Implications in unfolding/aggregation mechanisms. J. Dairy Sci. 94:5794-5810.

Relkin, P. 1996. Thermal unfolding of $\beta$-lactoglobulin, $\alpha$-lactalbumin, and bovine serum albumin. A thermodynamic approach. Crit. Rev. Food Sci. Nutr. 36:565-601.

René, F., and M. Lalande. 1988. Descriptions et mesures des phénomènes d'encrassement des échangeurs de chaleur. Cas du traitement thermique du lait. Entropie 139:13-23.

Santos, O., T. Nylander, K. Schillén, M. Paulsson, and A. C. Tragardh. 2006. Effect of surface and bulk solution properties on the adsorption of whey protein onto steel surfaces at high temperature. J. Food Eng. 73:174-189.

Sava, N., I. Van der Plancken, W. Claeys, and M. Hendrickx. 2005. The kinetics of heat-induced structural changes of $\beta$-lactoglobulin. J. Dairy Sci. 88:1646-1653.

Sawyer, W. H. 1968. Heat denaturation of bovine $\beta$-lactoglobulins and relevance of disulfide aggregation. J. Dairy Sci. 51:323-329.

Simmons, M. J. H., P. Jayaraman, and P. J. Fryer. 2007. The effect of temperature and shear rate upon the aggregation of whey protein and its implication for milk fouling. J. Food Eng. 79:517-528.

Spiegel, T. 1999. Whey protein aggregation under shear conditionsEffects of lactose and heating temperature on aggregates size and structure. Int. J. Food Sci. Technol. 34:523-531.

Stading, M., and A. M. Hermansson. 1991. Large deformation properties of $\beta$-lactoglobulin gel structures. Food Hydrocoll. 5:339-352.

Verheul, M., S. P. F. M. Roefs, and K. G. De Kruif. 1998. Kinetics of heat-induced aggregation of $\beta$-lactoglobulin. J. Agric. Food Chem. 46:896-903.

Xiong, Y. L., K. A. Dawson, and L. Wan. 1993. Thermal aggregation of $\beta$-lactoglobulin: Effect of $\mathrm{pH}$, ionic environment and thiol reagent. J. Dairy Sci. 76:70-77. 